\section{Marketing Turístico Estratégico: posicionamento da cvc Turismo no mercado brasileiro}

Strategic Tourism Marketing: Positioning "crc Turismo" in the Brazilian travel market

\section{Regina Ferraz Perussi ${ }^{1}$} Mirian Rejowski $i^{2}$

RESUMO: O presente artigo refere-se a uma pesquisa exploratória a respeito do marketing estratégico das agências de turismo no Brasil, centrada em estudo de caso sobre o posicionamento da Cvc Turismo no mercado de viagens nacional. Na parte teórica, trata de aspectos conceituais de segmentação de mercado, estratégias competitivas e posicionamento estratégico. $\mathrm{Na}$ pesquisa de campo, aborda o caso da cvc Turismo, agência de turismo sediada em São Paulo (Brasil), ressaltando as bases de segmentação e as estratégias competitivas por ela utilizadas. Os resultados indicam que o seu posicionamento estratégico é explicado pela busca de uma maior segmentação da demanda e da oferta de produtos turísticos, e pela existência de várias estratégias, como sua ampla rede de distribuição no Brasil, seus preços e formas de pagamento e seu foco de atuação no turismo interno. Conclui que há uma posição de liderança da CVC no mercado turístico e que essa empresa situa-se na fase de consolidação do seu ciclo de vida.

PALAVRAS-CHAVE: marketing turístico; agência de turismo; posicionamento estratégico; bases de segmentação; estratégias competitivas; CVc Turismo; São Paulo; Brasil.

\footnotetext{
1. Bacharel em Turismo e mestre em Ciências da Comunicação pela Universidade de São Paulo. Docente do Curso de Turismo da Faculdade SENAC, Cásper Líbero e UNifieo. Contato: Rua Ponta Porã, 203/44 - 05058-000 - São Paulo-sp; e-mail: reginaferraz@perussi@gmail.com.

2. Bacharel em Turismo, doutora em Ciências da Comunicação e livre-docente em Teoria do Turismo e do Lazer pela Universidade de São Paulo. Docente do Mestrado em Turismo da Universidade de Caxias do Sul. Contato: Av. Francisco Getúlio Vargas, 1.130, Bloco 46 - 95070-560 - Caxias do Sul-RS; e-mail:mirwski@usp.br / mrejowsk@ucs.br.
}

ABSTRACT: Exploratory research about strategic marketing of the tourism agencies in Brazil, centralized in case study of the positioning "cvc Turismo" in travel market. It aims identify ways of utilization of strategic marketing of the tourism agencies with the purpose in the maintenance in travel market. On the theoretical part, treats conceptual aspects of tourism agencies and strategic marketing, detaching privatestudies in touristic enterprises. On field research approaches "Cvc Turismo" (Sao Paulo) case, beginning from its historic and general characterization and emphasizing the basis of segmentation and competitive strategies used by itself. The results shows its strategic positioning is explained by the search of larger segmentation of demand and of the offer of touristic products and existence of many strategies, like its extensive distribution net in Brazil, its prices and payment ways and its actuation focus in internal tourism. Concluding there is a leadership positioning of the $\mathrm{CVC}$ in the touristic market and this enterprise is in consolidation stage about its life cycle.

KEYWORDS: tourism marketing; tourism agency; strategic positioning; basis of segmentation; competitive strategies; “cvc Turismo",Sao Paulo, Brazil.

\section{Introdução}

No mundo contemporâneo, as empresas das mais diversas áreas de atuação têm percebido cada vez mais a premente necessidade de identificar seus clientes, reais e potenciais, e atingir, de forma plena, seus anseios e expectativas, a fim de sobreviverem à acirrada competitividade do mercado. Para alcançar tal intento, é preciso conhecer profundamente esse público, o que só é possível mediante a pesquisa de segmentação de marketing, considerando a diversidade da demanda atual. Nesse sentido, a elaboração e a implementação de estratégias competitivas, adequadas às corporações, tornam-se imprescindíveis para estabelecer seu posicionamento em seu mercado de atuação.

O presente artigo faz parte da dissertação de mestrado defendida por uma das autoras, pela ECA/USP, em abril de 2004. Trata, especificamente, dos resultados obtidos com a operadora turística CVC Turismo no que se refere à sua segmentação de mercado, e do posicionamento estratégico no setor de agenciamento no`Brasil.

Em termos metodológicos, trata-se de uma investigação exploratório-descritiva, cuja pesquisa de campo foi efetuada a partir de visitas e observação in loco na matriz e em filiais da empresa; de entrevistas semi-estruturadas com dirigentes e responsáveis pelos setores de operação e comercialização da empresa, além do diretor-geral e de seu assessor, no período de maio de 2003 a janeiro de 2004; e 
da coleta de dados no site oficial da empresa, em folhetos, reportagens, anúncios e outros materiais institucionais.

$\mathrm{A} \mathrm{CrC}^{3}$ Turismo é uma operadora de turismo de grande porte, que atua em todo o Brasil, com turismo emissivo e receptivo, efetuando o atendimento direto aos clientes, tanto pessoas físicas quanto jurídicas, e intermediando os serviços entre estes, as agências de viagens e os prestadores dos serviços turísticos. É considerada a maior operadora turística do Brasil e uma das maiores da América Latina, segundo seus dirigentes, pelo fato de possuir um market share (fatia de mercado) de $60 \%$ do setor nacional, o maior volume de faturamento e de passageiros transportados do país.

É relevante o papel dessa empresa na construção da história do turismo no Brasil, por ter sido pioneira em diversas ações que propiciaram o desenvolvimento do mercado de viagens, tais como a utilização de uma rede integrada de computadores, facilitando a comunicação entre suas filiais espalhadas em todo o Brasil. Além disso, foi uma das primeiras operadoras a fretar aeronaves inteiras, sendo considerada hoje a maior empresa nesse segmento no país. Destacou-se, também, por ter sido a empresa que deu início à utilização de um canal de comunicação direto com o cliente, a partir da criação do SAC - Serviço de Atendimento ao Cliente. Seu empreendedorismo pioneiro também se refletiu na inauguração da primeira loja virtual de turismo do Brasil, no ano de 2000.

\section{Marketing estratégico: segmentação e posicionamento}

Segundo Moraes (2000: 16), as empresas possuem dois tipos de ações de marketing para se dirigir ao mercado: a difusão e a segmentação. Enquanto a primeira visa ao estabelecimento de um produto único para todos os tipos de consumidores, a segunda entende que o público é heterogêneo e, por esse motivo, os esforços devem se concentrar em apenas algumas fatias dessa demanda, com o intuito de poder atender plenamente às suas expectativas.

Nesse sentido, Kotler e Armstrong (1999) dividiram o marketing em: marketing de variedade de produtos e marketing de massa, conforme o tipo de produção dos produtos. $\mathrm{O}$ primeiro apresenta escolhas diferenciadas para distinguir os produtos em relação ao concorrente, em contraposição ao segundo, que visa a produzir e distribuir um produto único ao mercado, tentando atrair os consumidores com essa oferta padronizada.

3. A Agência de Viagens CrC Tur Ltda. surgiu no ABC Paulista na década de 1970, mais precisamente em Santo André, no dia 28 de maio de 1972, por meio da associaçāo de Guilherme Paulus e de Carlos $V$ icente Cerchiari, ex-vereador da cidade na época, sendo que a origem do nome da empresa provém das iniciais de seu nome.
Como não é viável desenvolver um programa de marketing para cada cliente, adota-se a segmentação de mercado, a fim de propiciar um atendimento mais compatível às expectativas dos consumidores. Nesse sentido, adotou-se a seguinte conceituação de segmentação de mercado:

Agrupamento de indivíduos, cujas reações esperadas aos esforços de marketing serão semelhantes durante um determinado período de tempo, objetivando a determinação de diferenças significativas entre grupos de compradores, separando-os em conjuntos diferenciados, de maneira a possibilitar à empresa a seleção daqueles nos quais pareça mais conveniente concentrar seus esforços, robustecendo, com isto, a competitividade desta empresa em relação às suas concorrentes (Grisi, 1986).

Para realizar o marketing de segmentos, é necessário que se enfoque a segmentação no público em que se pretende atuar. Com esse objetivo foram estabelecidas as variáveis ou bases de segmentação:

- variáveis de medidas objetivas: são medidas sem muita discordância entre os pesquisadores, uma vez que seus dados geralmente são obtidos por meio de censos. É o caso das variáveis geográficas, demográficas e socioeconômicas;

- variáveis de medidas subjetivas ou comportamento inferido: referem-se às construções mentais dos consumidores, geralmente registradas em levantamentos e entrevistas. Como exemplos dessa classificação são citadas as variáveis psicográficas e comportamentais.

Além dessas variáveis, no caso do setor turístico, Beni (1998: 149) afirmou que:

um dos principais meios para segmentar o mercado é através da identificação do motivo da viagem, que pode variar entre turismo e lazer, negócios e compras, desportivo, ecológico, rural, de aventura, religioso, cultural, científico, gastronômico, estudantil, de congressos e eventos, familiar e amigos, de saúde ou médico-terapêutico.

Essa divisão do mercado favorece a criação de políticas de preços e promoções direcionadas para cada público-alvo, atendendo às suas expectativas específicas.

De acordo com Tomanari (2003: 35) e Swarbrooke e Horner (2002: 140), há também a segmentação por benefício, que demonstra a divisão do mercado segundo as vantagens que os consumidores buscam em uma determinada categoria ou tipo de produto ou serviço.

Não basta que uma organização possua um conjunto sofisticado de modelos e técnicas, pois, para obter sucesso, estes precisam explorar sua capacidade competitiva 
e encontrar vantagens diante de seus concorrentes. Para enfrentar os desafios ambientais, uma organização precisa superar os recursos da concorrência, tanto em termos humanos como financeiros, tecnológicos e produtivos. Nesse sentido, precisa lançar mão de estratégias competitivas, o que, segundo Porter (1996), significa:

A busca de uma posição competitiva favorável em uma indústria, a arena fundamental onde ocorre a concorrência. A estratégia competitiva visa a estabelecer uma posição lucrativa e sustentável contra as forças que determinam a concorrência na indústria.

Em geral, há um "valor" que os clientes se dispõem a pagar por um determinado produto ou serviço, e o "valor superior", conhecido como "preço-prêmio", decorre da oferta de preços mais altos que os da concorrência, com benefícios ou vantagens equivalentes ou, porém, compensados por diferenciais significativos. Além dos preços, a infra-estrutura, a qualidade dos serviços e a imagem da marca da empresa na mente do cliente são os principais elementos capazes não só de identificar a organização, mas, sobretudo, de diferenciá-la da concorrência.

A segmentação de mercado é de fundamental importância para o desenvolvimento do posicionamento dos produtos e serviços de uma empresa, e o objetivo da pesquisa de segmentação é analisar os mercados e encontrar os nichos para obter uma posição competitiva superior. Dessa forma, a escolha da estratégia é fundamental para melhorar a posição de uma empresa dentro de seu mercado de atuação.

Com o intuito de definir o seu posicionamento, uma empresa pode se utilizar de dois tipos de estratégias competitivas: liderança de custo e de diferenciação, segundo Porter (1996).

No caso da liderança de custo, a busca se concentra em encontrar uma vantagem competitiva baseada nos custos, por meio da produção ou da prestação de serviços turísticos com valores inferiores aos dos rivais. Dessa forma é possível vender mais barato e incrementar o volume de vendas no mercado, desestimulando a ação da concorrência e a entrada de novos concorrentes.

Torna-se relevante ressaltar que a lógica estratégica da liderança no custo geralmente exige que uma empresa seja a líder no custo, e não apenas uma dentre as diversas empresas que disputam essa posição.

Por sua vez, a estratégia de diferenciação consiste em mostrar que a empresa ou que alguns de seus produtos sejam percebidos como únicos pelos clientes. Isso permite à corporação cobrar um preço maior por eles, pois os clientes acreditam que não os encontrarão em outro lugar. A diferenciação pode ser considerada pela marca, pelo prestígio ou pela qualidade dos serviços, dentre outros fatores.

Porter (1996) ponderou que, dificilmente, uma corporação alcança liderança no custo e na diferenciação, tendo em vista que a diferenciação em si é quase sempre dispendiosa. Com outro enfoque, Kotler \& Armstrong (1999) afirmaram que a oferta de uma empresa pode ser diferenciada por suas linhas de produtos, serviços, funcionários ou imagem.

\section{Atuação da cvc Turismo no mercado brasileiro}

\section{Segmentação da oferta e demanda}

A pesquisa in loco permitiu uma divisão da segmentação de mercado segundo a oferta de produtos disponibilizados pela Cvc Turismo e de acordo com a clientela atual, ou seja, sua demanda real. Os resultados obtidos mostram uma segmentação geral entre as viagens internacionais e nacionais, num primeiro plano, seguindo o critério de medidas objetivas e enfatizando as variáveis geográficas.

As viagens internacionais organizadas apresentam-se segmentadas geograficamente por continente, região, país, grupos de cidades ou cidades isoladas, como, por exemplo: Europa, Europa Fácil, África do Sul, América do Sul, Taiti e suas Ilhas, Caribe, Estados Unidos e Canadá. Destaca-se a programação Europa Fácil por tratar-se de programas isolados por cidades, que podem ser conjugadas em diferentes produtos turísticos, conforme as necessidades e os desejos dos clientes.

Considerando as viagens nacionais e internacionais, a segmentação por meio de transporte se apresenta nas seguintes categorias: rodoviário, aéreo (vôos regulares), fretamentos (vôos charters), rodo-aéreo e marítimo (cruzeiros).

Referente aos roteiros nacionais, a segmentação ocorre de forma diferenciada: por tipo de produto ou motivo de viagem. Existem programações que proporcionam encontro com a natureza e a prática de esportes, referentes aos destinos do ecoturismo, alguns já mais conhecidos, outros ainda tidos como alternativos. Os pacotes são todos aéreos, incluindo, além da passagem de ida e volta, os traslados de chegada e saída, algum tipo de pensão alimentícia (café da manhã, meia pensão ou pensão completa), além de um city tour. ${ }^{4}$

4. Os destinos oferecidos são os seguintes: Amazônia (Amazonas); Aracaju e Cânion do Xingó (Sergipe); Praias do Sul da Bahia; Belém com Alter do Chão e/ou Ilha de Marajó (Pará); Chapada Diamantina (Bahia); Chapada dos Veadeiros (Goiás); Fortaleza com Camocim ou Jericoacoara (Ceará); Itacaré (Bahia); Pantanal e Chapada dos Guimarães (Mato Grosso); Refúgio Ecológico Caiman (Mato Grosso do Sul); Rota das Dunas de Fortaleza a Jericoacoara (Ceará); Rota do Sol de Natal a Fortaleza (Rio Grande do Norte e Ceará). 
Sobre o turismo de saúde, um dos lançamentos exclusivos da CVC se refere aos spas, intitulados como "Roteiros de Saúde, Bem-Estar e Lazer". Cada spa corresponde a um tipo de interesse de público, como os Spas de Destino, os spas localizados em resorts/hotéis, cruzeiros/Cruise Line Spa e os Day Spas; possui programas específicos de acordo com a seguinte tipologia: clínica naturista ou spa médico, holístico, ilha, esporte e aventura, nutrição e fitness, estético, butique, termal, bem-estar ou wellness ou, ainda, ortomolecular.

A respeito do turismo de eventos, a CVC criou, no final de 2003, uma nova divisão dentro da própria empresa, denominada “Cvc Eventos", para atender com exclusividade os passageiros de convençōes, congressos e feiras. Trata-se, na verdade, da evolução de sua experiência adquirida com a realização de eventos de grande porte e, segundo o diretor comercial da empresa, existem inúmeras vantagens nesse tipo de turismo.

Com relação ao turismo cultural, não existem programaçōes específicas elaboradas com este intuito, mas é possível afirmar que praticamente todos os roteiros envolvem o aspecto da cultura local, pois o turista geralmente está em busca de novas formas de pensar, agir e sentir. Mesmo dentro do próprio Brasil existem muitas variaçōes nas maneiras de falar e vestir, na expressão da culinária, do artesanato e da música, além do próprio patrimônio construído (igrejas, museus, monumentos etc.). Nos roteiros internacionais, a diferença cultural é maior, e mesmo que não queira ou perceba, o viajante está entrando em contato com uma realidade diferente do seu cotidiano.

No entanto, não existem itinerários especiais para o turismo de aventura ou turismo desportivo. Também não há roteiros direcionados ao turismo religioso ou gastronômico, tampouco voltados para a terceira idade e consumidores com necessidades especiais.

Sobre a exclusividade de operação de roteiros, sabe-se que a CVC foi e é pioneira em determinados produtos, que foram ou podem ser facilmente copiados por outras operadoras do mercado. Existem alguns produtos inéditos, como os itinerários de pesca dirigidos a turistas internacionais, saindo de Buenos Aires e de Miami para a cidade de Manaus; o pacote para a Cidade de Cabo Frio (RJ), via aérea, e os já citados roteiros de spas.

Além destes, merece destaque especial o programa "Visite São Paulo com a CvC", em comemoração ao aniversário de 450 anos da referida metrópole. Embora tenha focado a cidade em função de toda a programação dessa data comemorativa, na verdade, esse roteiro já vinha sendo realizado de forma incipiente desde 2002, envolvendo não só a capital do Estado, mas também outras cidades situadas em seu entorno.

Com relação à segmentação da demanda, a empresa dimensiona e identifica o seu público-alvo e respectivos segmentos graças ao banco de dados integra- do, que possui informaçōes de um milhão de clientes, sendo que 60 mil destes são considerados especiais pela freqüência na participação de seus roteiros. O investimento nesse banco de dados contribuiu para o cruzamento de dados, permitindo o registro do perfil e do histórico de cada cliente, e a formatação de anúncios e malas-diretas. Segundo seu diretor de marketing, "é sempre mais efetivo concentrar os esforços no público cujo perfil combina com o do produto e que já é nosso cliente" (Ciaffone, 2003).

Conforme os dados coletados, no perfil geral da demanda da empresa em questão prevalece a preocupação com a segmentação geográfica e sociodemográfica. Assim, de modo geral, a CvC considera o local de moradia dos turistas para definir a origem de seus vôos fretados, pois, embora a maioria dos embarques aéreos origine-se nas capitais dos Estados, também existem partidas de cidades do interior. É notável a participação massiva de clientes da região Sudeste e, principalmente, do Estado de São Paulo, que é o principal centro emissor de turistas do país. Com relação às outras características, notam-se as seguintes:

- sexo - uma pequena diferenciação a favor do sexo feminino (52\%) em termos do público em geral da CVC;

- estado civil - a maioria são pessoas solteiras, com uma participação de $50 \%$ do total;

- faixa etária - grande parte dos clientes são adultos, compreendidos entre 25 e 49 anos; percebe-se uma parcela pequena de crianças e jovens, enquanto as pessoas com mais de 60 anos representam uma significativa parcela - acima de 10\%;

- gasto médio por viagem - cerca de $47 \%$ dos clientes gastam, em média, na faixa de $R \$ 651,00$ a $R \$ 1.300,00$ por viagem; aproximadamente $92 \%$ dos clientes têm um gasto médio por pacote de até $\mathrm{R} \$ 2.100,00$; já o público mais elitizado é pequeno, com a participação de apenas 7,5\%.

Outras variáveis relacionadas à segmentação de demanda deveriam ser contempladas, tais como: ocupação ou profissāo, nível ou grau de instrução, estilo de vida ou comportamento. Como não se obtiveram dados em separado de tais categorias por ano no período analisado, não se pôde constatar qualquer tendência ascendente ou decrescente dessas categorias.

Além desses dados quantitativos de mensuração objetiva, identificaram-se variáveis de medidas subjetivas vinculadas a benefícios. Segundo seus dirigentes, a imagem da Cvc transmite idoneidade e prestígio de marca conhecida e respeitada em todo o Brasil. 


\section{Estratégias competitivas}

\section{Extensa e diversa oferta de produtos e serviços turisticos}

Como uma grande operadora, é imperativo que possua um extenso leque de produtos, com o objetivo de diversificação de roteiros e serviços como forma de atender a vários segmentos de público e atrair novos clientes, evitando a competição baseada única e exclusivamente no menor preço, segundo Kotler e Armstrong (1999).

Conforme o diretor comercial e operacional do Departamento Nacional da CVC, para garantir uma adequada prestação de serviços nos destinos, a empresa dispõe de equipes de receptivo local com atendimento personalizado durante 18 horas por dia, nos principais pontos em que atua no país, com grupo fixo de funcionários em 17 estados brasileiros. Isso sugere a incipiente estrutura do receptivo em alguns destinos turísticos brasileiros, com o que a operadora, para manter uma qualidade do seu produto turístico, se vê "obrigada" a implantar a sua própria estrutura local (Weeden, 2001).

Segundo Teich (2003: 64), "a cvc desfruta o virtual monopólio do turismo de massa brasileiro. São dela seis de cada dez pacotes turísticos vendidos no país". Apesar disso, a referida empresa já apresenta uma diversificação de produtos que se traduz não apenas em quantidade, mas sobretudo no aperfeiçoamento da qualidade de seus produtos. Assim como expresso em sua missão, a intenção é atingir diversos tipos de público, inclusive de maior poder aquisitivo, para tanto vem criando novos produtos nacionais, como os roteiros para os resorts, os cruzeiros marítimos e os spas, e incursionando no mercado internacional, com roteiros tradicionais e "exóticos" (Taiti e África do Sul).

Mesmo não sendo hoje uma empresa que atue exclusivamente com o turismo de massa, a CVC comercializa produtos com grande volume de turistas e, por esse motivo, não é correto afirmar que vise à sustentabilidade local como requisito fundamental. Conforme Weeden (2001), um número reduzido de pessoas por pacote tornaria o custo per capita mais elevado, o que inviabilizaria a realização de viagens estruturadas. Entretanto, seus dirigentes asseguram que o número máximo de passageiros a ser fixado para os pólos em lançamento, referentes a destinações semi-exploradas e "ecoturísticas", é significativamente menor que o de outros destinos em que o fluxo de visitantes já está consolidado e a infra-estrutura geral e turística encontra-se totalmente implantada.

\section{Foco de atuação no turismo interno}

Uma das principais estratégias para a consolidação da CVC no mercado brasileiro foi a concentração de sua atuação no turismo interno. No ano de 1994, no auge da paridade cambial, $60 \%$ dos pacotes da empresa eram internacionais e $40 \%$, nacionais, de acordo com Sambrana (2003: 50). No entanto, com a desvalorização do real em relação ao dólar, essa proporção mudou. Atualmente, $85 \%$ dos pacotes são para destinos domésticos; 10\%, internacionais; e 5\% para os cruzeiros marítimos (no Brasil ou no exterior).

Além disso, a falência das operadoras SOlETuR (outubro de 2001) e Stella Barros (fevereiro de 2003), que eram as maiores empresas do ramo no país, possibilitou de forma preponderante esse posicionamento, definitivo até o momento. Considerando que aquelas grandes empresas do turismo nacional dependiam fortemente das vendas de roteiros internacionais, com a alta do dólar, os valores dessas viagens se tornaram muito elevados na época, principalmente para a classe média. Tal situação resultou na abrupta redução dos rendimentos de tais organizações, uma vez que os clientes começaram a preferir itinerários dentro do próprio Brasil.

A CVC aproveitou essa oportunidade e buscou preencher a lacuna de mercado deixada pela SOLETUR, considerada a maior operadora de turismo do Brasil naquele período e, por conseqüência, sua concorrente direta, conforme se pode observar no comentário de Pozati (2002: 90-91):

O fato de a maior operadora brasileira decretar falência coloca em dúvida uma série de paradigmas, tanto entre as próprias agências de viagens como entre os clientes, agências e operadoras. Sem aviso prévio, uma empresa a qual os agentes de viagens vendiam literalmente de 'olhos fechados' decreta falência, deixando sem resposta aproximadamente sete mil turistas que já tinham comprado pacote pela empresa, em um total de 30 milhões de reais em dívidas junto a clientes, empregados e fornecedores, como cias. aéreas, empresas de receptivo e hotéis [...] pode-se tomar como exemplo as atitudes das cias. aéreas, que honraram seus compromissos junto aos clientes da extinta SOLETUR, operadoras concorrentes, como a CrC, que adotou muitos dos clientes da antiga arquiinimiga em seus pacotes (...).

Partindo-se da premissa básica de que um líder é aquele que está sempre em busca de inovações, a cvc fretou um navio (o Blue Dream R-5), considerado o mais moderno transatlântico a navegar pela costa brasileira, a fim de firmar essa marca de liderança de mercado, assumindo uma dívida de US $\$ 6$ milhões. Torna-se relevante salientar que, de acordo com o diretor do Departamento Marítimo da CVC, não existem, no mundo, mais de vinte operadoras que reúnam condições financeiras para tal feito, sendo a CVC uma dessas poucas empresas. 


\section{Ampla rede de distribuição no Brasil}

O alcance de uma ampla e crescente rede de distribuição de seus produtos, espalhada por todo o Brasil e constituída principalmente por lojas situadas em regiões privilegiadas com grande fluxo de público, é outra das estratégias da CVC em termos de competitividade. Sob esse aspecto, quase metade das filiais da empresa estão localizadas dentro de shopping centers ( 36 de seus 81 pontos-de-venda), onde há maior nível de segurança e as pessoas costumam usufruir seu tempo livre para diversão, sendo que uma parcela desse público pode ser suscetível à compra de produtos turísticos. Somado a isso, o horário de funcionamento desses centros de compras auxilia os consumidores a se dirigirem a uma agência de turismo. Enquanto a maioria dos concorrentes funciona até às $18 \mathrm{~h}$ ou $19 \mathrm{~h}$, as lojas dos shopping centers podem ficar abertas até às $22 \mathrm{~h}$. Embora a maior parte dos contratos seja efetivamente firmada nas filiais fora desses complexos comerciais, estes servem como um show-room, onde os clientes, principalmente os potenciais, podem ter o seu primeiro contato com os produtos e serviços oferecidos pela cvc Turismo.

É relevante enfatizar que a escolha dos pontos de vendas da cvc é feita por meio de minuciosa análise de viabilidade por regiões, estados e cidades brasileiras, levando-se em consideração os dados econômicos de renda e o número de habitantes do local para, posteriormente, efetivar a implantação da nova filial.

Tendo em vista que $85 \%$ das vendas dos produtos da empresa são concretizadas pelas agências de viagens coligadas (o restante está pulverizado em $12 \%$ pelas lojas e filiais, e $3 \%$ por meio da loja virtual), a cvc optou por propiciar uma comissão maior (12\%) para os agentes de viagens, que são seus principais representantes e distribuidores de produtos, ao passo que a maior parte das operadoras do trade paga apenas 10\%, conforme Sambrana (2003: 49). Segundo o seu presidente:

O sucesso da CVC vem da nossa boa relação com o agente de viagens. É ele que tem o contato direto com o cliente e nos dá todo o feedback. [...] é o agente de viagem que dá o feedback pra mim. Eu acompanho, leio, escuto, converso, estou constantemente me informando com ele (Motta, 2003: 10, 12).

Percebe-se, assim, a importância da distribuição indireta, pois as lojas e filiais próprias da CVC são responsáveis por apenas $15 \%$ da distribuição de seus produtos e serviços de forma direta.

\section{Preços e formas de pagamento}

A oferta de preços menores e as formas de parcelamento em maior número de prestações que as dos principais concorrentes é outra ferramenta que possibili- ta melhores oportunidades para a aquisição dos produtos oferecidos aos clientes. De acordo com o diretor-geral da empresa, "a venda de pacotes de turismo deve ser tão facilitada quanto a de eletrodomésticos". Assim entendida, faz uma analogia da Operadora CvC com as "Casas Bahia", afirmando que a empresa de turismo pode ser conhecida como "as Casas Bahia do Turismo" (Teich, 2003: 64-66). Além disso, seus dirigentes estão cientes de que a atividade turística tem concorrência direta com outros bens tangíveis, conforme relata o diretor comercial da empresa:

Meus concorrentes são os telefones celulares, os televisores, as roupas. A classe média empobreceu nos últimos anos. Se a pessoa trocar o aparelho celular deixa de fazer a viagem. É por isso que acompanho a tendência do varejo (Reigada, 2003: 8).

Deve-se ressaltar, entretanto, que a Cvc não é a empresa popular que, no passado, oferecia os preços mais baixos do mercado turístico brasileiro, pois, atualmente, alguns produtos ainda são mais baratos, porém outros apresentam um valor superior, em decorrência de serviços agregados e da busca de melhoria da qualidade. Segundo Pozati (2002: 49), "no Turismo, podemos citar como exemplo [...] a CvC e Panexpress (atual VARIG Travel) como operadoras sempre lembradas pela qualidade aliada ao preço em quaisquer pesquisas de opinião".

De acordo com Motta (2003), a cvc iniciou sua trajetória fazendo turismo popular e, na opinião de seu presidente, isso era necessário porque o turismo precisava se popularizar na época, ou seja, havia uma grande massa de pessoas que podiam viajar. "Sem volume de passageiros, não se consegue preço. Com volume e preço, você procura qualidade."

Para a obtenção dos preços mais competitivos, a cvc possui linhas de financiamento com instituições bancárias e empresas'de cartões de crédito, ou oferece crediário direto aos clientes, com taxas de juros mais baixas que a média do mercado.

Também com o objetivo de propiciar os preços mais baratos, procura disponibilizar as reservas com maior antecedência dos períodos de embarque, sobretudo nas épocas de alta temporada, pois, dessa forma, os clientes podem programar melhor suas viagens, pagando menos e em maior número de parcelas. Conforme o diretor de vendas da empresa, ao comentar essa estratégia, especificamente no caso das vendas para o navio Blue Dream:

Os preços serão progressivos e privilegiarão quem comprar mais cedo (...) Queremos educar o nosso passageiro a se programar com antecedência, o que é o normal no negócio de cruzeiros em todo o mundo (Ciaffone, 2003). 
Essa estratégia pode ser ilustrada, por exemplo, por um de seus folhetos de propaganda de mala-direta dos clientes, enviado durante a campanha de alta temporada de dezembro de 2002: "A CVC está oferecendo roteiros de alta temporada com preços de baixa" (...) Antecipe a compra da sua viagem cvc para a alta temporada e embarque com altas vantagens". Tais vantagens residem em "mais opções de escolha de hotéis, não corre o risco de entrar em lista de espera de vôos, consegue melhores assentos e preços, além de contar com condições especiais para pagar".

Quando se verifica a necessidade de redução dos preços dos pacotes, a preocupação da Cvc com a manutenção do nível de qualidade fica em primeiro plano, pois nenhum item do produto é eliminado, segundo seus dirigentes. Isso somente é possível por causa do bom relacionamento da Cvc com seus fornecedores, que confiam na parceria com a operadora pela segurança da concretização dos negócios.

É possível afirmar que, atualmente, muitos dos clientes da CvC aceitam pagar o chamado "preço-prêmio" para participar de seus programas de viagens, por conta da consolidação da imagem da organização em seu ramo de atuação, pois há uma confiança na garantia do bom serviço prestado. Segundo pesquisas realizadas pela própria empresa, como abordado por Weeden (2001), o público atual da CVC acredita que é válido fazer um investimento maior na aquisição de um produto de uma empresa por lealdade à sua marca ou pelo fato de que ela transmite credibilidade no mercado de viagens no país, proporcionando um preço avaliado como justo e com uma relação custo versus benefício positiva.

\section{Investimentos em tecnologia}

Nos últimos anos (até 2003), a CVC aplicou cerca de US $\$ 4$ milhões em tecnologia da informação, segundo seus dirigentes. $O$ final do século $x x$ foi marcado pelo sucesso do programa operacional e de vendas Systur, especialmente elaborado para a Cvc, contando com 670 terminais servidores interligados em todo o Brasil, com capacidade para 12 mil transações por minuto. Com o investimento no "Portal do Agente", os profissionais que atuam nas agências de viagens adquiriram muitas facilidades no seu trabalho cotidiano, sobretudo no setor de reservas e na impressão de contrato de prestação de serviços, passagens e vouchers, que podem ser efetivados por meio da Internet.

Outros investimentos observados in loco referem-se ao uso do GDS, do CDRom e do e-ticket, além do já citado banco de dados de clientes. Segundo o presidente da empresa:

Nós temos investimentos poderosos na informática - somos a única empresa de turismo que tem o portal do agente de viagem que ele pode acessar diretamente pela Internet, pegar roteiro, tabela etc. Não só o agente de viagem, mas também o passageiro pode ser ajudado (Motta, 2003: 11).

\section{Propaganda e inserção na mídia}

Efetivamente, a aplicação em propaganda pela $\mathrm{Cvc}$ é entendida como um compromisso com o cliente e abrange a confecção de materiais promocionais como prospectos diversos, malas diretas segmentadas e capas de vouchers diferenciadas. Todo o seu material publicitário é desenvolvido pela agência de publicidade Souza Aranha, sendo que, do seu faturamento de US $\$ 220$ milhões, aplica cerca de US $\$ 16$ milhões em publicidade (o que corresponde a um total de 7\% de seu faturamento), segundo Sambrana (2003: 50). A CVC, hoje, é a maior empresa anunciante nos veículos de comunicação de turismo do Brasil, ocupando espaços nobres nas publicações especializadas e na grande imprensa, conforme Ciaffone (2003).

$\mathrm{Na}$ opinião de Reich (2001), quando uma empresa ocupa a posição de destaque em seu mercado de atuação, não deve mudar suas estratégias de direcionamento nem necessita fazer vultosos investimentos promocionais. Embora possua estratégias definidas de posicionamento de mercado, os dirigentes da CvC não compartilham totalmente desta idéia, já que acreditam que o emprego de recursos financeiros em publicidade é primordial e deve ser freqüente, para que a empresa esteja sempre em evidência na mídia e, por conseguinte, seja sempre lembrada pelo público.

Essas peças publicitárias são bem elaboradas em termos de forma e conteúdo, constituindo-se em importantes instrumentos de divulgação e comercialização dos seus produtos. São amplamente utilizadas pelos promotores de vendas da empresa, que estão em contato direto e permanente com os agentes de viagens que distribuem estes produtos no mercado.

As malas-diretas são diferenciadas de acordo com o público-alvo, sendo confeccionadas conforme o perfil do cliente e as características de compra de produtos da Cvc, sendo enviadas nomeadamente para o cliente, informando que o contato deste deve ser feito junto à loja onde o mesmo efetuou sua última aquisição de produto. Dessa forma, procura-se estabelecer um vínculo com a filial, estreitando e dando continuidade ao relacionamento entre o cliente e a empresa.

Somente para divulgar o navio Blue Dream R-5, a empresa dirigiu US\$ 2 milhões de sua verba de marketing em ações de marketing de relacionamento. Para a mídia de massa, estão sendo reservados cerca de US\$ 800 mil, englobando campanhas em outdoors na Cidade de São Paulo e espaço em filmes comerciais na TV Globo, de acordo com Ciaffone (2003).

A boa relação da CVC com a imprensa é crucial para o seu posicionamento, já que constitui um indicador do fortalecimento da imagem da empresa no mercado. Periodicamente, são publicadas matérias, notas e citações na mídia especia- 
lizada ou geral, a respeito dos lançamentos da empresa, sua participação em eventos de porte do trade e o recebimento de valiosos prêmios de destaque.

\section{Workshop anual}

A realização do maior workshop organizado anualmente por uma única operadora, com um stand exclusivo para cada fornecedor, é outra estratégia da CVC, apontada por Kotler \& Armstrong (1999) como um elemento de diferenciação da imagem da empresa. O referido evento vem sendo ampliado gradativamente, no decorrer de nove edições, de 1994 a 2003, com o intuito de comportar não só um maior número de expositores, como, principalmente, de atrair um volume superior de visitantes. A princípio, foi realizado no Terraço Itália, depois foi transferido para o Pavilhão da Bienal do Ibirapuera e, posteriormente, passou a ocorrer na Expo Center Norte.

\section{Pesquisas de controle}

A fim de monitorar os resultados obtidos por meio das estratégias utilizadas, são efetivadas constantes análises e avaliações dos produtos e serviços, segundo recomendaram Kotler \& Armstrong (1999). Nesse sentido, a CVC procura medir o grau de satisfação da demanda real por meio da análise dos questionários de avaliação ou "opinários", respondidos pelos clientes ao final de cada viagem terrestre ou aérea, já que o formulário dos roteiros marítimos encontra-se em fase de finalização. Como exemplo, cita-se a conclusão final do relatório da pesquisa junto a 194 dos 293 clientes que viajaram para as Serras Gaúchas, no período de 21 a 28 de setembro de 2003, cuja avaliação é referente a embarque, transporte, receptivo, instalações e serviços do hotel, atendimento e avaliação geral:

[...] $98,06 \%$ dos clientes pesquisados [...] gostaram da viagem [...] Alguns clientes fizeram elogios [...] quanto ao hotel. Referente [...] a suas instalações, [...] quartos amplos e decorações, [...] pelo seu serviço de quarto, serviço prestado pelas camareiras e pela agilidade do atendimento.

Os demais elogios [...] foram: para a empresa CVC, pelo comprometimento desde o embarque até o retorno da viagem e para a filial 9.800 (Osasco), pelo bom atendimento.

[...] alguns clientes sugeriram: embarque mais próximo de sua cidade (São José do Rio Preto), diversidade dos restaurantes, dos passeios e informações adicionais quanto à forma de pagamento dos passeios (cheque, dinheiro ou cartão). [...] mesmo com algumas insatisfaçōes, os clientes pesquisados gostaram da viagem [...] e também do hotel [...], onde puderam desfrutar do conforto e do bom atendimento, assim informado pelos clientes.
Considerando que o nível de insatisfação dos clientes, expressados pelos conceitos "regular" e "insatisfeito" nessa pesquisa, ficou de 0 a 3,1\%, representando $1,4 \%$ do total dos clientes pesquisados, as poucas reclamações não são relevantes para uma ação junto aos prestadores turísticos dessa viagem. Quando ocorrem duas reclamações semelhantes sobre o mesmo produto, empresa, funcionário ou serviço, a CVC toma ações corretivas.

Além dos "opinários", os dados do SAC incluídos no cadastro dos clientes se constituem em importantes fontes de controle de seus clientes reais.

Não são empreendidas investigações para se identificarem as falhas ou desvantagens dos concorrentes, conforme mencionado por seu assessor, pois, segundo os administradores da empresa em pauta, o foco é o cliente atual, e não os concorrentes, segundo apontaram Ries \& Trout (1999), até pela grande diferença existente entre as duas maiores operadoras brasileiras: a primeira, a CVC, e a segunda, cujo nome a CVC não revela.

\section{Outras}

Uma outra estratégia é o estabelecimento do nome CVC, que se utiliza da "economia fonética", como abordados por Ries \& Trout (1999), identificando a marca e a imagem da operadora no mercado.

Para o diretor de marketing da empresa, com o logotipo da CVC elaborado em forma de elipse, pretende-se transmitir uma imagem de modernidade e dinâmica global, que envolve todas as pessoas. Isso quer dizer que a referida empresa busca atrair qualquer tipo de cliente para que o mesmo possa conhecer seus produtos e usufruir de seus serviços.

Por fim, ainda, o fretamento do navio Blue Dream, na temporada de verão 2003/2004, traduz uma importante estratégia de marketing. Isso porque, além de ser mais um produto diferencial destinado a atingir determinado segmento de público, objetiva firmar a posição da empresa como líder no mercado turístico brasileiro.

\section{Considerações finais}

Para resistir aos períodos de recessão econômica, de acordo com Josephides (1993), além de apostar no mercado interno, uma empresa deve possuir uma diversidade de produtos e dispor de equipamentos próprios. Esse é exatamente o caso da CVC Turismo, que possui pacotes aéreos, terrestres e marítimos, tanto nacionais quanto internacionais, e é também proprietária de hotéis e empresas de receptivo local em inúmeras localidades turísticas. 
Uma estratégia também recomendada por Josephides (1993) para uma empresa de turismo sobreviver às épocas de crise - e que a CvC realmente atendediz respeito aos vôos charters que partem de aeroportos no interior dos estados, destacando-se da concorrência, que normalmente possui embarques originários apenas das principais capitais brasileiras.

Portanto, no momento vigente, pode-se afirmar que a cvc possui a liderança geral do mercado de operadoras de turismo no Brasil em virtude de três fatores primordiais:

- relação custo versus benefício com maior acessibilidade na aquisição dos produtos (ora pelos preços menores, ora pela facilidade de pagamento, com variedade de formas e condições propiciadas aos clientes);

- diversidade de produtos oferecidos, com extensa gama de roteiros para os inúmeros segmentos de demanda;

- preocupação com o incremento constante na qualidade dos serviços oferecidos, com uma acurada seleção de seus colaboradores, tanto funcionários diretos e indiretos quanto fornecedores.

Sob este prisma, não há nenhum concorrente no mesmo patamar para a CVC Turismo, não só no Brasil como na América Latina, segundo seus dirigentes. Podem ser citadas a TAM Viagens e a VARIG Travel como concorrentes no quesito preço, já que são operadoras de baixo custo, porém não possuem a variedade de roteiros disponibilizados pela CVC Turismo. Porém, a Agaxtur e a Nascimento podem concorrer com a CVC no setor marítimo, mas a diversidade de opções de cruzeiros e o volume de passageiros da CvC são superiores. Logo, pode-se ratificar que alguns produtos da CVC são concorrentes de outras operadoras, mas a empresa como um todo não possui uma concorrente direta.

Para Teich (2003: 66), “alguns administradores de resort não escondem o temor de que, por falta de concorrentes à altura, a CvC acabe ditando as regras do mercado de turismo brasileiro".

No que tange ao posicionamento geral da Cvc Turismo, pôde-se constatar que a empresa não apresenta nenhum dos erros de posicionamento, conforme apontados por Kotler \& Armstrong (1999), como:

- subposicionamento, já que tanto os clientes reais quanto os potenciais possuem uma imagem clara e definida da empresa;

- superposicionamento, pois a organização visa a transmitir uma imagem de operadora não-especializada em certo tipo de produto ou segmento de mercado;
- posicionamento confuso, já que se encontra bem estabelecida em seu ramo de atuação.

Isso significa que, de acordo com a fase do ciclo de vida, a cvc Turismo se posiciona, no momento atual, no estágio de consolidação.Ainda, a empresa segue os princípios mencionados por Cooper et al. (2001) como indicadores da posição estratégica de uma empresa no mercado, como:

- economia de escala com o objetivo de oferecer preços competitivos;

- rede de distribuição com cobertura nacional;

- busca permanente de tecnologias mais avançadas para poder aperfeiçoar o processo de produção e comercialização.

O estilo de gerenciamento adotado pelos diretores e gerentes da CvC se reflete na posição ocupada pela empresa em seu ramo de atuação, pois as competências e habilidades destes estimulam a criatividade dos colaboradores para implementar novos produtos e procedimentos, facilitando as operações e impulsionando as vendas. Aliado a isso, influenciam as estratégias competitivas a serem adotadas pela corporação e, conseqüentemente, seu sucesso no trade e aumento de market share.

Salienta-se, com os resultados obtidos nesta pesquisa, a premente necessidade de colaboração espontânea dos administradores das empresas com as investigações da universidade, na tentativa de conciliar a teoria com a prática, pois tanto o mercado quanto a academia podem, juntos, fomentar e incrementar a gestão do turismo neste país.

Pode-se dizer que a concorrência possui um lado perverso, mas também uma face positiva, haja vista que, com a livre competição, as empresas são forçadas a crescer, desenvolver e se aperfeiçoar em vários aspectos. Assim, a posição de liderança da CVC Turismo no mercado pode influenciar outras operadoras a buscar a melhoria do padrão de qualidade de seus produtos e serviços, adequando-se às tendências da globalização e permitindo um maior comprometimento com as expectativas de seu público e com as da sociedade.

\section{Referências bibliográficas}

BENI, Mário Carlos. 2000. Análise estrutural do turismo. São Paulo: SENAC-SP.

CIAFFONE, Andréa. 2003. cvc investe US\$ 8 milhōes para navegar com diferenciais. Gazeta Mercantil, São Paulo, 16 ju.

GRISI, Celso. 1986. Contribuições ao estudo das técnicas de segmentação de mercado: uma análise de dados sobre os apostadores da Loteria Federal. Dissertação (Mestrado) - FEA/USP, São Paulo. 
KOTLER, Philip \& ARMSTRONG, Gary. 1999. Princípios de marketing. 7. ed. Rio de Janeiro: ITC. MORAES, Cláudia Corrêa de Almeida. 2000. Turismo - segmentação de mercado: um estudo introdutório. In: ANSARAH, Marília Gomes dos Reis (Org.). Turismo-segmentação de mercado. 2. ed. São Paulo: Futura.

MOTTA, Edson. 2003. Entrevista com Guilherme Paulus, presidente da cvc. Em Hotelaria Profissional. São Paulo: SINTHORESP, p. 10-12.

PORTER. Michael E. 1996. Vantagem competitiva: criando e sustentando um desempenho superior. Rio de Janeiro: Campus.

POZATI, Fábio. 2002. A importância da qualidade no atendimento como estratégia de marketing turístico em agências de viagens: estudo de caso: Ramazini Turismo - Ribeirão Preto - SP. Dissertação (Mestrado) - ECA/USP, São Paulo.

REICH, Allen Z. 2001. Determining a firm's linear market position: in search of an effective methodology. Journal of Hospitality \& Tourism Research, Arizona: Sage Publications Thousand Oaiks, v. 25, n. 2, may, p. 159-172.

REIGADA, Maria Izabel. 2003. cvc Eventos abre escritório em SP. Jornal Panrotas. São Paulo: Panrotas, ano XI, n. 577, 2-8 dez., p. 24.

RIES, Al \& TROUT, Jack. 1999. Posicionamento: a batalha pela sua mente. São Paulo: Pioneira. SAMBRANA, Carlos. 2003. O vôo da CVC. Isto é Dinheiro. São Paulo: Editora Três, n. 308, 23 jul., p. 48-50.

SWARBROOKE, John \& HORNER, Susan. 2002. O comportamento do consumidor no turismo. São Paulo: Aleph.

TEICH, Daniel Hessel. 2003. O dono dos pacotes. Veja. São Paulo: Abril, ed. 1.828, ano 36, n. 45, 12 nov., p. 64-66.

TOMANARI, Sílvia Assumpçāo do Amaral. 2003. Segmentação de mercado com enfoque em valores e estilo de vida (segmentação psicográfica): um estudo exploratório. Dissertação (Mestrado) - ECA/USP, São Paulo.

VIAGEM E TURISMO. 2004. Relax para todos. Editora Abril, ano 10, n. 1, jan., p. 104.

WEEDEN, Clare. 2001. Ethical tourism: an opportunity for competitive advantage? Journal of Vacation Marketing. Reino Unido: Henry Stewart, vol. 8, n. 2, p. 141-153.

Recebido em: 24/03/2005.

Aprovado em: 14/05/2005.

Revista impressa em janeiro de 2006.

Tiragem: 1.300 exemplares. 